\title{
Synthesis of $\mathrm{LiFePO}_{4}$ in situ vapor-grown carbon fiber (VGCF) composite cathode material via microwave pyrolysis chemical vapor deposition
}

\author{
DENG Fei ${ }^{1}$, ZENG XieRong ${ }^{2,3^{*}}$, ZOU JiZhao ${ }^{2,3}$, HUANG JianFeng ${ }^{3}$, SHENG HongChao ${ }^{1}$, \\ XIONG XinBo ${ }^{2,3}$, QIAN HaiXia ${ }^{2,3}$ \& LI XiaoHua ${ }^{2,3}$ \\ ${ }^{1}$ School of Materials Science and Engineering, Northwestern Polytechnical University, Xi' an 710072, China; \\ ${ }^{2}$ College of Materials Science and Engineering, Shenzhen University, Shenzhen 518060, China; \\ ${ }^{3}$ Shenzhen Key Laboratory of Special Functional Materials, Shenzhen 518060, China
}

Received August 30, 2010; accepted October 13, 2010; published online May 10, 2011

\begin{abstract}
One of the most important factors that limits the use of $\mathrm{LiFePO}_{4}$ as cathode material for lithium ion batteries is its low electronic conductivity. In order to solve this problem, $\mathrm{LiFePO}_{4}$ in situ vapor-grown carbon fiber (VGCF) composite cathode material has been prepared in a single step through microwave pyrolysis chemical vapor deposition. The phase, microstructure, and electrochemical performance of the composites were investigated. Compared with the cathodes without in situ VGCF, the initial discharge capacity of the composite electrode increases from 109 to $144 \mathrm{~mA} \mathrm{~h} \mathrm{~g}^{-1}$ at a $0.5-\mathrm{C}$ rate, and the total electric resistance decreases from 538 to $66 \Omega$. The possible reasons for these effects are proposed.
\end{abstract}

vapor-grown carbon fiber, $\mathrm{LiFePO}_{4}$, microwave, chemical vapor deposition, lithium ion batteries

Citation: Deng F, Zeng X R, Zou J Z, et al. Synthesis of $\mathrm{LiFePO}_{4}$ in situ vapor-grown carbon fiber (VGCF) composite cathode material via microwave pyrolysis chemical vapor deposition. Chinese Sci Bull, 2011, 56: 1832-1835, doi: 10.1007/s11434-010-4273-2

$\mathrm{LiFePO}_{4}$ (LFP) can be used as cathode material for lithium ion batteries [1]. It has a relatively large theoretical capacity of $170 \mathrm{~mA} \mathrm{~h} \mathrm{~g}$, good thermal stability in fully charged states and exhibits little hygroscopic behavior. In addition, this material is inexpensive, nontoxic, and environmentally benign [2,3]. However, the electronic conductivity of pure LFP $\left(10^{-10}\right.$ to $10^{-9} \mathrm{~S} \mathrm{~cm}^{-1}$ [4]) is several orders of magnitude lower than that of other important cathode materials $\left(\sim 10^{-3}\right.$ $\mathrm{S} \mathrm{cm}^{-1}$ for $\mathrm{LiCoO}_{2}$ [5] or $10^{-4} \mathrm{~S} \mathrm{~cm}^{-1}$ for $\mathrm{LiMn}_{2} \mathrm{O}_{4}$ [6]). Therefore, lattice doping [4] or surface coating methods [7-10] have been attempted to overcome this weakness.

Vapor-grown carbon fiber (VGCF) has been reported as ideal conductive filler in electrodes, because of their excellent mechanical properties and high electrical and thermal conductivity [11-13]. The first discharge capacity of VGCF enhanced LFP composites was more than two times of those without VGCF [14]. Nevertheless, ball milling, the most widely used

\footnotetext{
*Corresponding author (email: zengxier@szu.edu.cn)
}

method to introduce conductive additives in the mixing process, could inevitably damage their initial structure and increase the contact resistance between additives [14-16].

Higuchi et al. were the first to apply microwave in the preparation of LFP [17]. Microwave can ensure uniform and fast heating through a self-heating process based on direct microwave energy absorption by the materials [18]. Microwave pyrolysis chemical vapor deposition (MCVD) has ever been used to obtain VGCF in our previous work [19]. In this paper, MCVD technology was developed to synthesize in situ network-like VGCF-improved LFP cathode with enhanced electronic conductivity.

\section{Experimental}

\subsection{Synthesis}

$\mathrm{FeC}_{2} \mathrm{O}_{4} \cdot 2 \mathrm{H}_{2} \mathrm{O}, \mathrm{NH}_{4} \mathrm{H}_{2} \mathrm{PO}_{4}$, and $\mathrm{LiOH} \cdot \mathrm{H}_{2} \mathrm{O}$ in a $1: 1: 1$ molar 
ratio were dispersed into $75 \mathrm{wt} \%$ (compared to the raw materials) alcohol, and then 5.4 wt\% carbon black (SuperP Erachem, Maryland, USA) was added to the mixture. The mixture was mixed with a ball mill at $300 \mathrm{r} \mathrm{min}^{-1}$ for $6 \mathrm{~h}$. After being dried under vacuum at $120^{\circ} \mathrm{C}$ for $12 \mathrm{~h}$, the samples were placed in a home-made quartz reactor installed in the MCVD equipment [20] (Figure 1). After the chamber was with argon, the MCVD equipment was operated at 2.45 $\mathrm{GHz}$, with an output power of $800 \mathrm{~W}$. One kind of samples, designated as "VC/LFP", was prepared at a temperature range of $550-800^{\circ} \mathrm{C}$. When the temperature reached the setting value, the quartz reactor was exposed to a propylene flow of $90 \mathrm{sccm}$ for $10 \mathrm{~min}$, and then the MCVD equipment was closed. For comparison, another test sample, "C/LFP", was also obtained at the same conditions, but there was no propylene used in the synthesis process.

\subsection{Characterization}

X-ray powder diffraction (XRD, D8 ADVANCE, Bruker $\mathrm{AXS}$ ) with $\mathrm{Cu} \mathrm{K} \alpha$ radiation was used to identify the phases. An integrated Raman spectroscopy system (inVia Reflex, Renishaw) was used to analyze the structure and composition. The excitation wavelength was supplied by an internal Ar $(514.5 \mathrm{~nm}) 20 \mathrm{~mW}$ laser. A field emission scanning electron microscope (FESEM, S-4800, HITACHI) and energy dispersive X-ray spectroscopy (EDS, EDAX, New Jersey, USA) were used to analyze the morphology and elementary components, respectively.

\subsection{Electrochemical properties}

The cathodes containing $95 \mathrm{wt} \%$ active materials and $5 \mathrm{wt} \%$ polyvinylidene fluoride (PVDF) were prepared by spreading a slurry in N-methylpyrrolidone (NMP) onto aluminum foil current collectors and allowing them to dry. 2032-size coin cells were assembled in an argon-filled glove box, using lithium as a counter electrode and $1 \mathrm{M} \mathrm{LiPF}_{6}$ in $1: 2$ ethylene carbonate/dimethyl carbonate (EC/DMC) as the electrolyte

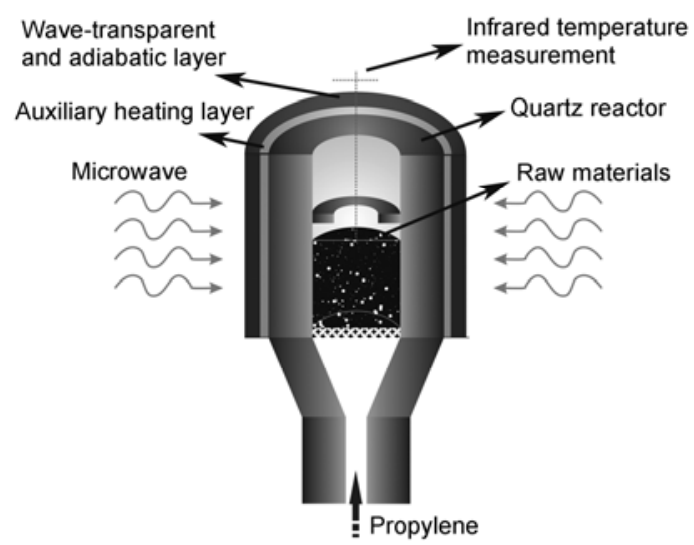

Figure 1 Sketch of the MCVD reactor. solution. Charge-discharge tests were performed using an Arbin Instruments' BT2000 (Texas, USA) at $25^{\circ} \mathrm{C}$. Electron impedance spectroscopy (EIS) was measured with a frequency response analyzer (Solatron 1260, California, USA) interfaced with a potentio-galvanostat (Solatron 1287).

\section{Results and discussion}

The XRD spectrum shown in Figure 2(a) of VC/LFP can be attributed to a major phase of orthorhombic LFP (JCPDS: 83-2092) and a minor phase of rhombohedral graphite-3R (JCPDS: 26-1079), except for several weak diffraction peaks of orthorhombic $\mathrm{Li}_{3} \mathrm{PO}_{4}$ (JCPDS: 15-0760). The mean crystallite size of LFP is $\sim 72 \mathrm{~nm}$, which was calculated from the widths of the major diffraction peaks of (200), (101), and (311) using Scherrer's formula. The diffraction peaks of graphite result from the carbon black mixed in the raw materials. The phase content of LFP, C, and $\mathrm{Li}_{3} \mathrm{PO}_{4}$, are calculated using the semiquantitative method of relative intensity to a reference and are $\sim 84 \mathrm{wt} \%$, $\sim 14.5 \mathrm{wt} \%$, and $\sim 1.5 \mathrm{wt} \%$, respectively. The Raman spectra of the VC/LFP and carbon black used in the raw materials are shown in Figure 2(b) and (c). The bands at 500-100 $\mathrm{cm}^{-1}$ and $1120-520 \mathrm{~cm}^{-1}$ correspond to the Raman vibrations of $\mathrm{Fe}-\mathrm{O}$ and $\mathrm{PO}_{4}{ }^{3-}$ in $\mathrm{LFP}$, respectively [21], but
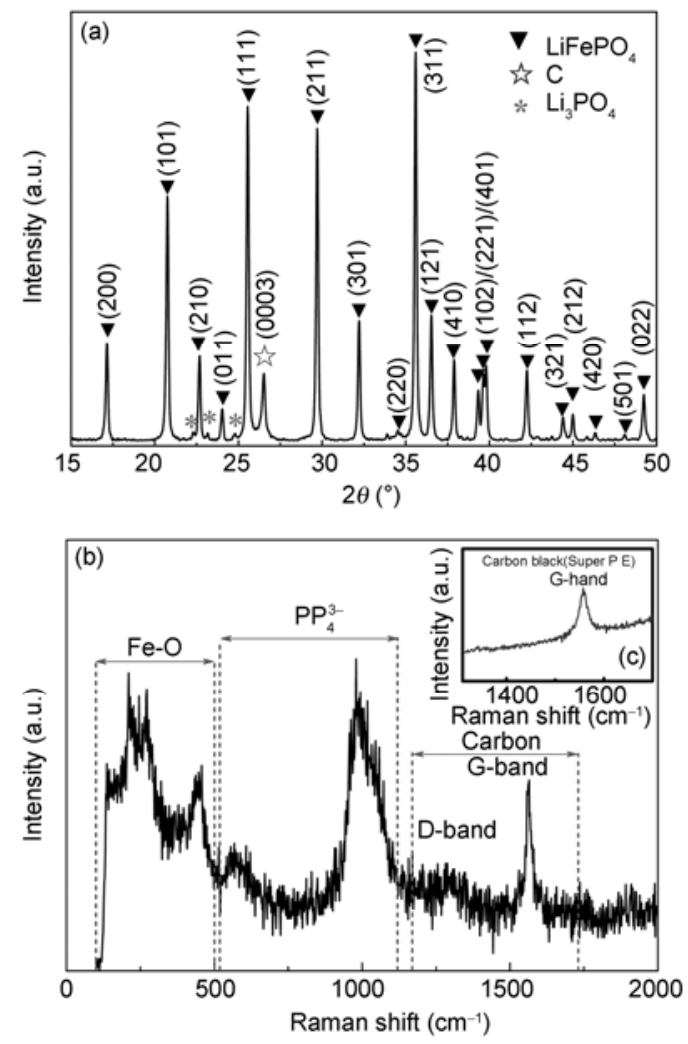

Figure 2 (a) XRD spectrum and (b) Raman spectrum of VC/LFP synthesized via MCVD at $650^{\circ} \mathrm{C}$; (c) Raman spectrum of the carbon black used as a raw material. 
the bands in the range of $1460-1170 \mathrm{~cm}^{-1}$ and $1730-1470$ $\mathrm{cm}^{-1}$ can be assigned to the D-band (disorder-induced phonon mode) and G-band (graphite band) of carbon, respectively. Compared with the Raman spectrum of the pure carbon black used as a raw material, the ratio of the $D / G$ integrated peak intensities much greater.

The typical FESEM morphology shown in Figure 3(a) and EDS analyses (not shown here) of the VC/LFP indicate that the VC/LFP is composed of sphere-like LFP, flaky graphite, and network-like fibers. From Figure 3(b), it can be seen that most VGCF grows on the surface of the graphite particles, and from further magnified image shown
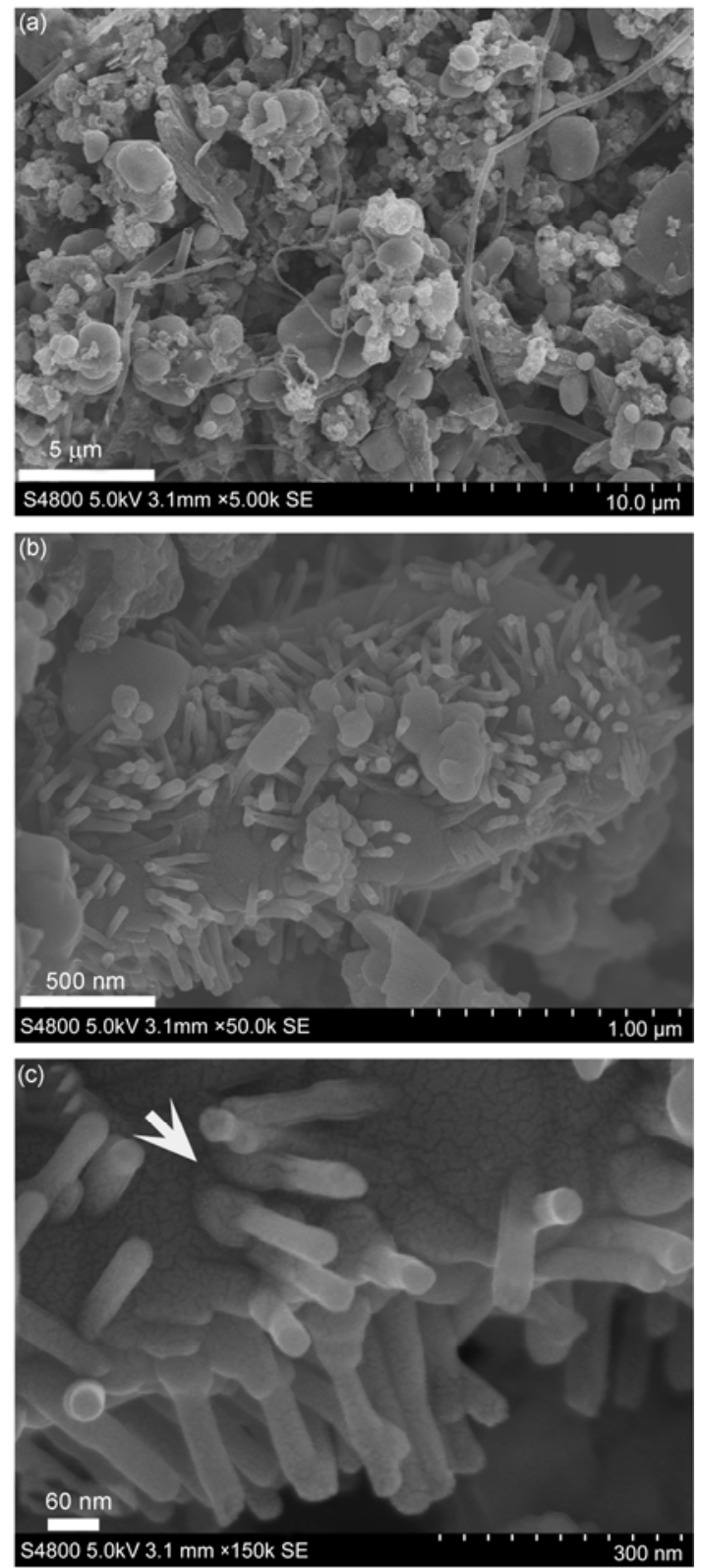

Figure 3 (a) FESEM image of VC/LFP synthesized via MCVD at $700^{\circ} \mathrm{C}$; (b) the FESEM morphology of VGCF observed on the surface of graphite particles in VC/LFP obtained via MCVD at $600^{\circ} \mathrm{C}$; (c) higher magnification. in Figure 3(c), an in situ growth mode can be seen. The in situ formation of VGCF can be attributed to the pyrolysis and deposition of propylene under the effects of microwave heating and/or the self-catalytic action of the raw materials (e.g. $\mathrm{FeC}_{2} \mathrm{O}_{4} \cdot 2 \mathrm{H}_{2} \mathrm{O}$ ). In addition, the turbostratic graphite formed near the surface of the VGCF [13] may give some clues to the proper interpretation of the weak D-band in the Raman spectrum (see Figure 2(b)).

The electrochemical performance of the VC/LFP cathodes, which is shown in Figure 4, is better than that of C/LFP cathodes. The initial discharge capacity of the $\mathrm{VC} / \mathrm{LFP}$ cathodes are $148 \mathrm{~mA} \mathrm{~h} \mathrm{~g}^{-1}$ and $144 \mathrm{~mA} \mathrm{~h} \mathrm{~g}^{-1}$ at a $0.1-\mathrm{C}$ rate and a $0.5-\mathrm{C}$ rate, respectively, which are slightly better than those of some other materials [14]. Furthermore, the cycling capacity fading in VC/LFP cathodes is negligible.

The impedance spectra of C/LFP and VC/LFP cathodes, which are shown in Figure 5, are both combinations of a depressed semicircle at high frequencies and a straight line at low frequencies. In the high-frequency region, the intercepts with the real impedance $\left[Z_{\mathrm{re}}^{\prime}\right]$ axis, which correspond to electron jumping, vary from 538 to $66 \Omega$. The decrease in total electric resistance could be ascribed to the in situ formation of VGCF networks in the cathodes. In the lowfrequency area, the slope of the impedance of VC/LFP is greater than that of C/LFP, indicating that the network-like VGCF improves the electrochemical activity of LFP effectively.

\section{Conclusions}

In situ network-like VGCF-improved $\mathrm{LiFePO}_{4}$ composite cathode material for lithium ion batteries has been synthesized using a MCVD method in the temperature range between $550^{\circ} \mathrm{C}$ and $800^{\circ} \mathrm{C}$. As a result of the in situ growth mode of the network-like VGCF formed on the graphite particles, the composite cathodes show satisfactory rate behavior

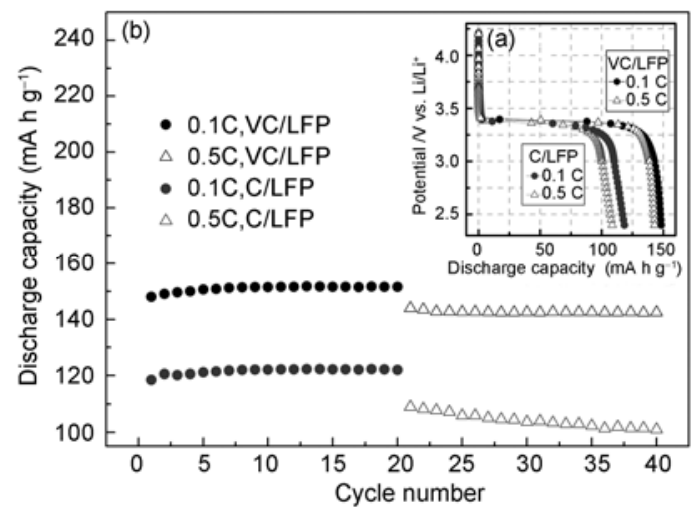

Figure 4 (a) Discharge curves and (b) cycling performance of VC/LFP and C/LFP (both obtained via MCVD at $650^{\circ} \mathrm{C}$ ). The cathode's performance was measured at different rates at $25^{\circ} \mathrm{C}$. 


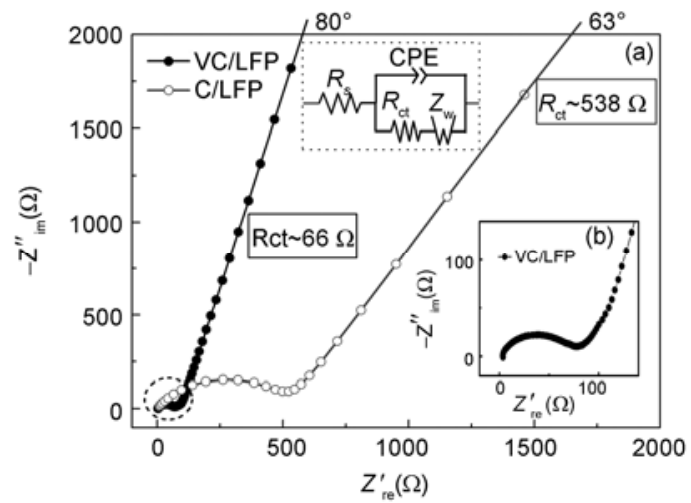

Figure 5 (a) EIS traces for VC/LFP and C/LFP (both obtained via MCVD at $650^{\circ} \mathrm{C}$ ) composite cathodes and (b) enlarged EIS trace for VC/LFP of the elliptic dashed zone shown in (a); the symbols $R_{\mathrm{s}}, R_{\mathrm{ct}}, Z_{\mathrm{w}}$, and CPE denote the solution resistance, the charge-transfer resistance, the Warburg impedance, and the constant phase angle element, respectively.

and cycling life. This study shows that it is possible to synthesize high-performance VGCF-improved $\mathrm{LiFePO}_{4}$ cathode material through a simple low-cost high-efficiency process.

This work was supported by the National Natural Science Foundation of China (50672059).

1 Padhi A K, Najundaswamy K S, Goodenough J B. Phospho-olivines as positive-electrode materials for rechargeable lithium batteries. $\mathrm{J}$ Electrochem Soc, 1997, 144: 1188-1194

2 Padhi A K, Najundaswamy K S, Masquelier C, et al. Effect of structure on the $\mathrm{Fe}^{3+} / \mathrm{Fe}^{2+}$ redox couple in iron phosphates. $\mathrm{J}$ Electrochem Soc, 1997, 144: 1609-1613

3 Padhi A K, Najundaswamy K S, Masquelier C, et al. Mapping of transition metal redox energies in phosphates with NASICON structure by lithium intercalation. J Electrochem Soc, 1997, 144: 2581-2586

4 Chung S Y, Bloking J T, Chiang Y M. Electronically conductive phospho-olivines as lithium storage electrodes. Nat Mater, 2002, 1: $123-128$

5 Molenda J, Stoklosa A, Bak T. Modifications in the electronic structure of cobalt bronze $\mathrm{Li}_{x} \mathrm{CoO}_{2}$ and the resulting electrochemical properties. Solid State Ionics, 1989, 36: 53-58

6 Guan J, Liu M. Transport properties of $\mathrm{LiMn}_{2} \mathrm{O}_{4}$ electrode materials for lithium-ion batteries. Solid State Ionics 1998, 110: 21-28

7 Huang H, Yin S C, Nazar L F. Approaching theoretical capacity of $\mathrm{LiFePO}_{4}$ at room temperature at high rates. Electrochem Solid-State Lett, 2001, 4: A170-A172

8 Ravet N, Goodenough J B, Besner S, et al. Improved iron based cathode material. In: 196th Meeting Abstract of the Electrochemical Society, 1999, Oct 17-22, Hawaii. Meeting Abstracts, 1999. 127

9 Belharouak I, Johnson C, Amine K. Synthesis and electrochemical analysis of vapor-deposited carbon-coated $\mathrm{LiFePO}_{4}$. Electrochem Commun, 2005, 7: 983-988

10 Croce F, Epifanio A D, Hassoun J, et al. A novel concept for the synthesis of an improved $\mathrm{LiFePO}_{4}$ lithium battery cathode. Electrochem Solid-State Lett, 2002, 5: A47-A50

11 Tatsumi K, Zaghib K, Sawada Y, et al. Anode performance of vapor-grown carbon fibers in secondary lithium-ion batteries. J Electrochem Soc, 1995, 142: 1090-1096

12 Endo M, Nishimura Y, Takahashis T, et al. Lithium storage behavior for various kinds of carbon anodes in ion secondary battery. J Phys Chem Solids, 1996, 57: 725-728

13 Endo M, Kim Y A, Hayashi T, et al. Vapor-grown carbon fibers basic properties and their battery applications. Carbon, 2001, 39: 12871297

14 Chen C C, Liu M H, Chen J M. Influence of addition of VGCF on $\mathrm{LiFePO}_{4}$ cathode materials in Li-ion batteries. In: 206th Meeting of the Electrochemical Society, 2004, Oct 3-8, Hawaii. Meeting Abstracts, 2004. 413

15 Li X L, Kang F Y, Bai X D, et al. A novel network composite cathode of $\mathrm{LiFePO}_{4} /$ multiwalled carbon nanotubes with high rate capability for lithium ion batteries. Electrochem Commun, 2007, 9: 663-666

16 Jin $\mathrm{B}$, Jin E M, Park $\mathrm{K} \mathrm{H}$, et al. Electrochemical properties of $\mathrm{LiFePO}_{4}$-multiwalled carbon nanotubes composite cathode materials for lithium polymer battery. Electrochem Commun, 2008, 10: 15371540

17 Higuchi M, Katayama K, Azuma Y, et al. Synthesis of $\mathrm{LiFePO}_{4}$ cathode material by microwave processing. J Power Sources, 2003, 119-121: 258-261

18 Park K S, Son J T, Chung H T, et al. Synthesis of $\mathrm{LiFePO}_{4}$ by co-precipitation and microwave heating. Electrochem Commun, 2003, 5: 839-842

19 Zou J Z, Zeng X R, Xiong X B, et al. Preparation of vapor grown carbon fibers by microwave pyrolysis chemical vapor deposition. Carbon, 2007, 45: 828-832

20 Zeng X R, Deng F, Zou J Z, et al. Preparation of carbon-coated $\mathrm{LiFePO}_{4}$ by microwave heating method. PRC Patent, CN101714634A, 2010-05-26

21 Burba C M, Frech R. Raman and FTIR spectroscopic study of $\mathrm{Li}_{x} \mathrm{FePO}_{4}(0 \leqslant x \leqslant 1)$. J Electrochem Soc, 2004, 151: A1032-A1038

Open Access This article is distributed under the terms of the Creative Commons Attribution License which permits any use, distribution, and reproduction in any medium, provided the original author(s) and source are credited. 